\title{
In Vivo Detection of Ultraviolet Photoproducts and Their Repair in Purkinje Cells
}

\author{
Fumio Ide, Naoko lida, Yoko Nakatsuru, Hideaki Oda, Osamu Nikaido, and \\ Takatoshi Ishikawa
}

Department of Molecular Pathology (FI, NI, YN, HO, TI), Graduate School of Medicine, University of Tokyo, Tokyo; and Division of Radiation Biology (ON), Faculty of Pharmaceutical Science, Kanazawa University, Kanazawa, Japan

SUMMARY: We previously developed a highly sensitive method to assess in situ repair kinetics of ultraviolet (UV)-induced DNA photoproducts in epidermal cells using monoclonal antibodies specific for cyclobutane pyrimidine dimers (CPDs) and pyrimidine-pyrimidone (6-4) photoproducts (64PPs) by immunohistochemistry. In order to determine whether nucleotide excision repair capacity is operative in postmitotic mature neurons, brain surfaces of adult mice were exposed to UVB, and induction and removal of CPDs and 64PPs in Purkinje cell DNA were assessed immunohistochemically. UVB penetrated brain tissue to a depth sufficient to allow quantitative study. CPDs but not 64PPs were clearly detectable in the nuclei of Purkinje cells at doses $>500$ $\mathrm{J} / \mathrm{m}^{2}$, in a dose-dependent manner. A time course experiment showed a statistically significant decrease of CPDs with time after irradiation. Although there was no apparent removal on Day 1, about half of CPDs were removed within 5 days, and the repair was essentially completed by Day 10 . We conclude that non-dividing cerebellar neuronal cells can indeed repair UV-induced DNA damage, but with relatively low efficiency as compared with dividing epidermal cells. (Lab Invest 2000, 80:465-470).

$S_{\text {is }}$ hort-wavelength ultraviolet B (UVB, 280-320 nm) is known to produce several photolesions in DNA. Major among these are the cyclobutane pyrimidine dimers (CPDs) and pyrimidine-pyrimidone (6-4) photoproducts (64PPs) (Moan and Peak, 1989), the critical components of the solar spectrum for the induction of skin cancer (Setlow, 1974). It is well-established that these photoproducts can be rapidly excised from DNA by the nucleotide excision repair (NER) system. We have developed a highly sensitive immunohistochemical method to detect CPDs and 64PPs directly in conventional paraffin-embedded histologic sections of human and animal skins using monoclonal antibodies specific for these photoproducts. Our results showed that epidermal cells of monkey and mouse are very efficient at repairing UV photoproducts, although species differences have been noted (Qin et al, 1994, 1995, 1996). Although it must be admitted that the present immunohistochemical method detects the DNA photolesions themselves and not the entire process of the NER, this system should be useful for in vivo studies of NER in various organs.

Controversy remains as to whether the NER pathway is functional in neurons of the adult brain (Brodsky et al, 1984; Brooks, 1998; Mazzarello et al, 1992; Scherini and Mares, 1993). In most studies, NER has been assessed by measurement of unscheduled DNA synthesis, but this method lacks specificity. The aim for this experiment is to investigate whether bulky

Received September 22, 1999

Address reprint requests to: Dr. T. Ishikawa, Department of Molecular Pathology, Graduate School of Medicine, University of Tokyo, 7-3-1 Hongo, Bunkyo-ku, Tokyo 113-0033, Japan. Fax: 813-5802-3346.
DNA lesions induced by UVB are repaired in neuronal cells of the adult mouse brain. To our knowledge, this is the first demonstration of dose-dependent induction and removal of CPDs in non-dividing neurons. Although UVB exposure is not physiological for brain, it may represent a suitable model for studying the mechanism of NER in Purkinje cells in vivo.

\section{Results}

\section{Dose-Dependent Induction of Photoproducts in Purkinje Cells}

CPDs were clearly demonstrable in the nuclei of Purkinje cells. The monoclonal antibody, TDM-2 did not show any binding activity to the control brain (unexposed to UVB). As shown in Fig. 1, UVB penetrated fully to the depth of the granule cell layer of the cerebellum, as evidenced by homogeneous staining of cell nuclei. In the cerebral cortex, neurons down to the level of the external pyramidal layer were stained with TDM-2 (data not shown). The relative staining intensities increased dose-dependently $(p<0.01)$. CPDs were detectable at the lowest dose of $500 \mathrm{~J} / \mathrm{m}^{2}$, and their formation increased at a relatively constant rate. The dose-response curve showed increases up to a plateau at low-doses $\left(250,500\right.$, and $\left.1000 \mathrm{~J} / \mathrm{m}^{2}\right)$ (Fig. 2). The observed plateau might be related to the fact that immunostaining intensity of the nuclei may not correlate with actual photoproduct numbers at higher dose, because antibody binding might be saturated, thereby limiting quantitative evaluation. On the other hand, 64PPs were not detectable under the same experimental conditions. 


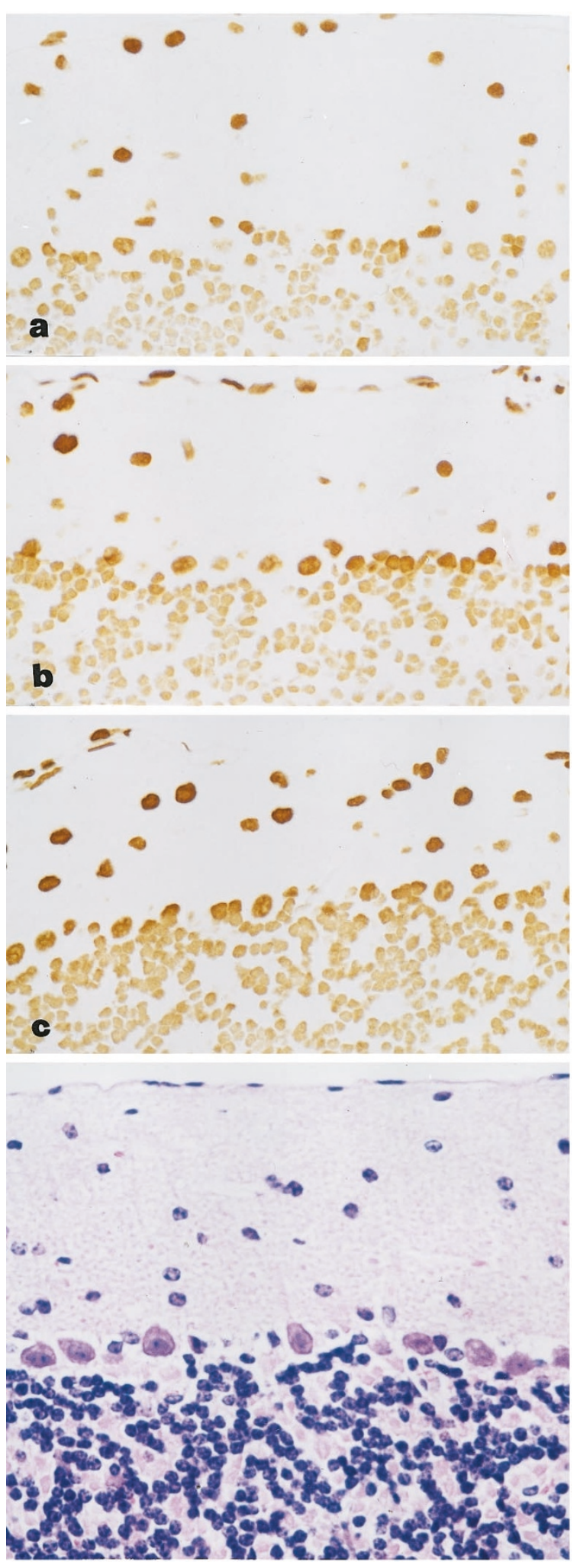

Figure 1.

Representative photomicrographs illustrating dose-dependent induction of CPDs in cerebellar neuronal cells with UVB irradiation: $a, 500 \mathrm{~J} / \mathrm{m}^{2} ; \mathrm{b}$, $1000 \mathrm{~J} / \mathrm{m}^{2} ; c, 3000 \mathrm{~J} / \mathrm{m}^{2}$. Because of their ease of identification, Purkinje cells, parallel to the brain surface were specifically examined in the present experiments. Hematoxylin and eosin (lower).

\section{Time Course Analysis of CPDs in Purkinje Cells}

Representative photomicrographs of time changes in CPDs are shown in Fig. 3. No removal was apparent within the first 1 day, but gradual decreases were detectable afterward (Fig. 4). Within 5 days, about half of CPDs were removed. As shown in Figs. 3 and 4, staining had almost completely disappeared by day 10. Similar results were obtained for neuronal cells of the cerebral cortex and the cerebellar granule cell layer (data not shown).

\section{Discussion}

In this study we clearly demonstrated that NER is indeed operative in postmitotic neuronal cells whose loss cannot be reversed by cellular renewal. The formation and removal of UV-induced DNA photolesions have been extensively studied in rodent and human skin (Berton et al, 1997; Burren et al, 1998; Bykov et al, 1999; Chadwick et al, 1995; Mitchell et al, 1995; Qin et al, 1994, 1995, 1996; Young et al, 1996). However, no reports have appeared concerning in situ immunohistochemical investigation of the NER process in non-dividing neuronal cells. DNA damage and its repair in the brain after treatment with genotoxic agents have traditionally been measured either by biochemical analysis of DNA strand breakage or by induction of unscheduled DNA synthesis (Gaubatz and Tan, 1994; Gobbel et al, 1998; Hadjiolov and Venkov, 1975; Ishikawa et al, 1978a, 1978b; Korr et al, 1989, 1997, Korr and Schultze, 1989; Morris et al, 1999; Rao, 1993; Rao and Loeb, 1992; Schmitz et al, 1999; Subrahamanyam and Rao, 1991; Wheeler and Lett, 1972, 1974). However, in biochemical studies, in which the brain is treated as a whole without excluding contamination of non-neuronal cells, artificial DNA breakage and rejoining tend to occur, and the unscheduled DNA synthesis assay is not a direct demonstration of NER. The present immunohistochemical method, in contrast, is highly sensitive and specific for detection of photoproducts at the cell level. In fact, it earlier allowed clear demonstration of CPDs in human epidermal DNA exposed to solar light for only 5 minutes (unpublished data).

The results obtained in this study showed CPDs to be generated in Purkinje cells exposed to a dose of $500 \mathrm{~J} / \mathrm{m}^{2}$ and above. We have no explanation for the lack of detection of 64PPs in neuronal cells. In general, their accumulation is usually low, being approximately $10 \%$ to $50 \%$ of the yield of CPDs (Moan and Peak, 1989). Moreover, 64PPs might somehow be rapidly eliminated from neuronal cells during irradiation and material processing, since 64PPs are induced at a greater frequency in DNA that is more accessible to repair enzymes (Gale and Smerdon, 1990; McCready and Cox, 1993; Mitchell et al, 1990). In fact, a time course study using the mouse skin system showed that about half of 64PPs were excised within the first 24 hours after irradiation, and the excision process was complete by 72 hours. In contrast, there was no apparent removal of CPDs in the first 24 hours, and 


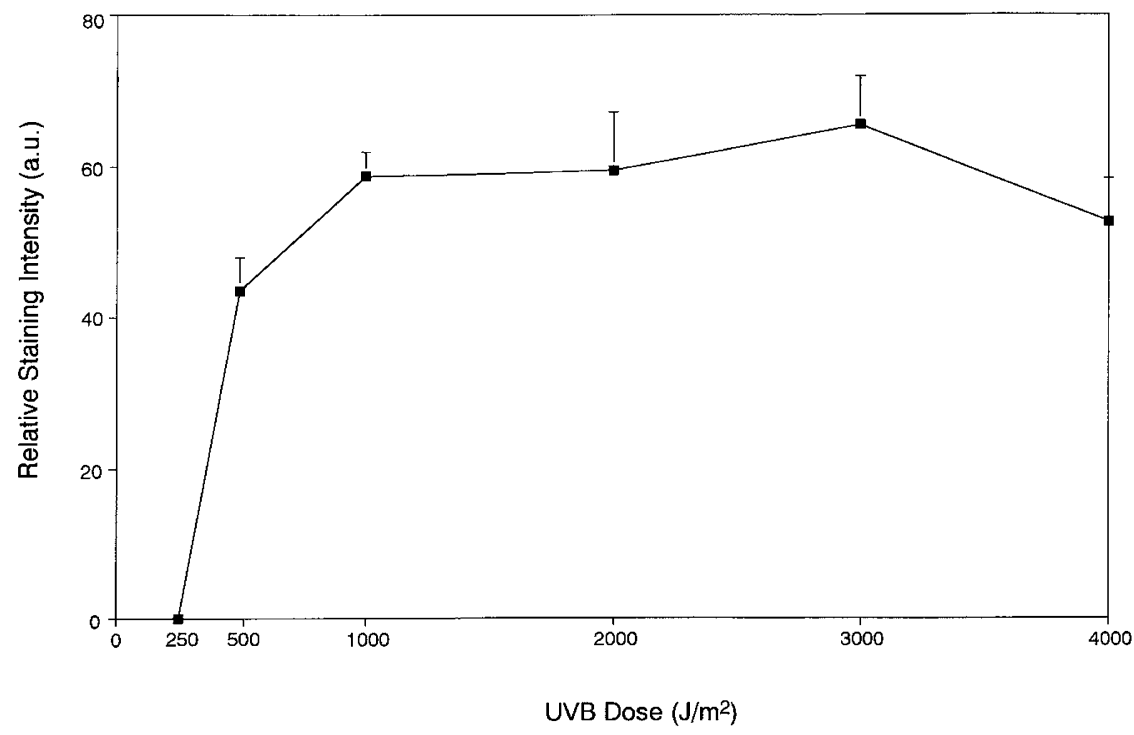

Figure 2.

Dose-dependent induction of CPDs. Relative staining intensities (au, arbitrary units) are plotted against UV dose. Each point represents the mean intensity for 5 mice. The bars indicate SD values. Regression analysis demonstrated a significant correlation between CPD formation and dose $(p<0.01)$.

they had only disappeared completely at 120 hours after irradiation (Qin et al, 1995). It is also interesting to note that CPDs but not for 64PPs could be demonstrated in human skin sections exposed to 1-hours natural sunlight (unpublished data). The exact explanation for the lack of detection of 64PPs in neuronal cells will require further study.

The time course studies revealed that removal of CPDs started with a time lag almost 2 days after irradiation and that the repair process was completed by 10 days. Since our previous reports indicated that $10 \%$ of CPDs were removed from the mouse epidermis during the first 24 hours following exposure to a dose of $500 \mathrm{~J} / \mathrm{m}^{2}$, with complete disappearance within 5 days (Qin et al, 1995), non-dividing neuronal cells are evidently less efficient at CPD removal than dividing epidermal cells. Regarding interspecies differences in photoproduct removal, we previously reported that mouse epidermal cells can efficiently repair UVphotoproducts, but with considerably less efficiency than monkey skin cells (Qin et al, 1994, 1995). Concerning other repair mechanisms, it is worth noting that neuronal cells can repair $\mathrm{O}^{6}$-methylguanine, mediated by the specific enzyme $0^{6}$-methylguanine DNA methyltransferase. Evidence from animal and cell culture systems indicates that repair of $\mathrm{O}^{6}$-alkylguanine protects cells from malignant conversion (Nakatsuru et al, 1993). For example, the carcinogen $\mathrm{N}$-ethyl-Nnitrosourea is known to induce tumors preferentially in tissues, such as brain, having low levels of $\mathrm{O}^{6}$ methylguanine DNA methyltransferase (Oda et al, 1997).

Using the approach adopted here, we have obtained preliminarily data suggesting that cerebellar neurons of mice lacking the xeroderma pigmentosum complementation group A gene fail to repair UVinduced DNA damage and show apoptotic cell death within 5 days after irradiation. Interestingly, heterozy- gous xeroderma pigmentosum group A gene targeted mice exhibited similar results as Crj: CD-1 (ICR) mice (unpublished data). The present method should be useful for further studies of NER in various types of mature neuronal cells in vivo.

\section{Materials and Methods}

\section{UVB Source}

Three fluorescent tubes (Toshiba FL 20 SE sunlamp, Toshiba Lighting and Technology Corporation, Tokyo, Japan), delivering an average dose of $3.8 \mathrm{~J} / \mathrm{m}^{2} / \mathrm{s}$ at a distance of $30 \mathrm{~cm}$ over the wavelength range of 280-340 nm with a main peak at $312 \mathrm{~nm}$, were used. This range includes approximately $90 \%$ of the total energy output of the lamp. In all experiments, the dose rate was measured using a Blak-Ray Ultraviolet Meter, J-221 (UVP Incorporation, San Gabriel, California).

\section{Animals and Experimental Procedures}

Crj: CD-1 (ICR) mice (3 weeks old) were purchased from Charles River Japan Incorporation (Kanagawa, Japan) and housed in a controlled environment with a 12-hour light/dark cycle. At 6 weeks of age, female mice were anesthetized with sodium pentobarbital and fixed rigidly in parallel to the UV lamp. After an incision in the head skin, a flap was elevated from the underlying bone and a portion of the skull was surgically removed to expose the brain. Irradiation with UVB was then performed. For the dose response experiments, the mice were killed immediately after irradiation. For the time course studies of photoproduct removal, after exposure to UVB at a dose of 1000 $\mathrm{J} / \mathrm{m}^{2}$, primary skin coverage was obtained with a local skin flap. Irradiated brains were excised on the planned days after treatment. For each dose or time point, 5 mice were used. All brain samples were fixed 


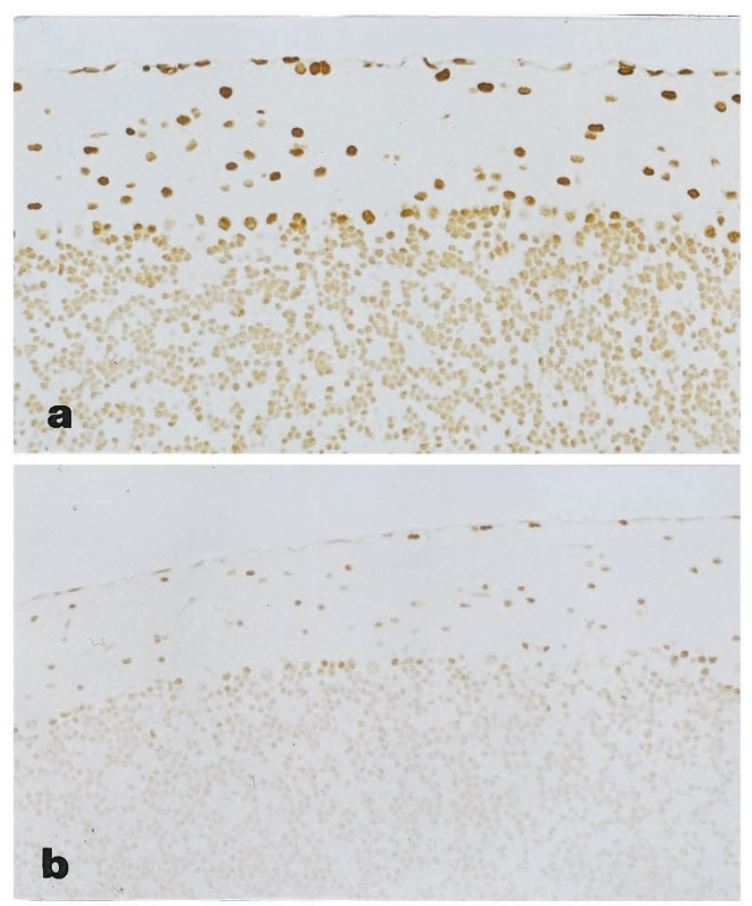

C

\section{d}

e

\section{Figure 3}

Photomicrographs illustrating removal of CPDs with time in Purkinje cells after UVB $1000 \mathrm{~J} / \mathrm{m}^{2}$ irradiation: a, 0 day; b, 3 days; c, 5 days; $d, 7$ days; e, 10 days. in $10 \%$ neutral buffered formalin and embedded in paraffin. To obtain identical staining conditions, control and irradiated tissues were embedded in the same paraffin blocks.

\section{Reagents}

Monoclonal antibodies, TDM-2 and 64M-2, against CPDs and 64PPs, respectively, were raised and characterized as described previously (Mori et al, 1991). Trypsin and 3,3'-diaminobenzidine, tetrahydrochloride were obtained from Wako Pure Chemical Industries (Osaka, Japan). A histofine SAB-PO (M) kit was purchased from Nichirei Corporation (Tokyo, Japan).

\section{Immunohistochemical Staining Procedures}

The methods applied were described in detail in our previous reports (Qin et al, 1994, 1995, 1996). Briefly, sections were pretreated with $70 \mathrm{~mm} \mathrm{NaOH}$ for 30 minutes at room temperature and then with $0.1 \%$ trypsin solution for 15 minutes. Subsequently, the avidin-biotin-peroxidase complex method was performed, using the monoclonal antibodies TDM-2 $(1: 1500)$ or $64 \mathrm{M}-2(1: 1000)$ at $4^{\circ} \mathrm{C}$ overnight. $\mathrm{A}$ $0.025 \% 3,3^{\prime}$-diaminobenzidine solution was applied as the chromogen. All slides were stained concurrently, and appropriate control sections were included in every staining run. No counterstaining was applied.

\section{Measurement of Nuclear Staining Intensity}

Nuclear staining intensity was quantified using a SP500F color image analyzer (Olympus, Tokyo, Japan). To record images, a $40 \times$ objective lens was used. For each sample on slides, the intensity of nuclear staining of consecutive cells was measured, for a total 50 Purkinje cells in the interfolding areas of the cerebellar folia, because these are parallel to the brain surface (Fig. 1). Background counting, for subtraction from the intensity values of the UV-exposed nuclei, was performed using the control samples on each slide. The results were expressed as relative staining intensity using arbitrary units (a.u.), and regression levels were calculated. The significance of differences was judged by the $t$ test.

\section{References}

Berton TR, Mitchell DL, Fischer SM, and Locniskar MF (1997). Epidermal proliferation but not the quantity of DNA photodamage is correlated with UV-induced mouse skin carcinogenesis. J Invest Dermatol 109:340-347.

Brodsky WY, Marshak TL, Mikeladze ZA, Moskovkin GN, and Sadykova MK (1984). DNA synthesis in the Purkinje neurons. Basic Appl Histochem 28:187-194.

Brooks PJ (1998). Detection of excision nuclease in cell-free extracts from the adult mammalian brain. Mutat Res 408:3746.

Burren R, Scaletta C, Frenk E, Panizzon RG, and Applegate LA (1998). Sunlight and carcinogenesis: Expression of p53 and pyrimidine dimers in human skin following UVA I, UVA II 


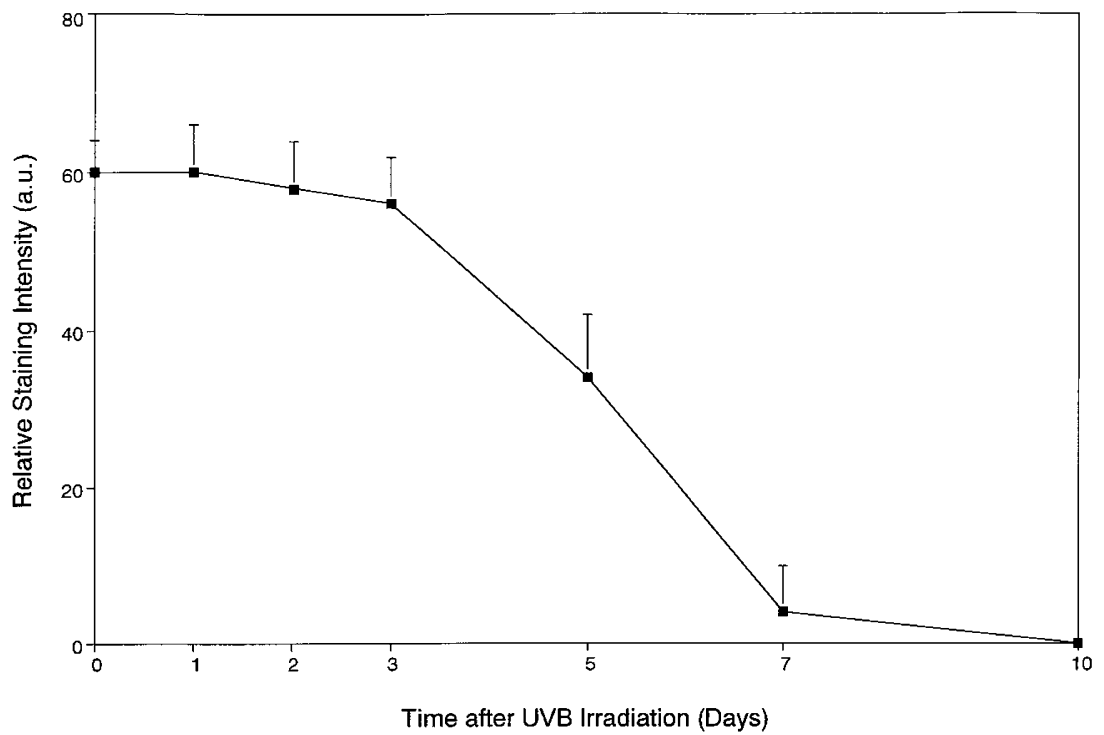

Figure 4.

Removal of CPDs in Purkinje cells after UVB 1000J/ $\mathrm{m}^{2}$ irradiation. Each point represents the mean intensity for 5 mice. The bars indicate sD values.

+ UVA II, and solar simulating radiations. Int $\mathrm{J}$ Cancer 76:201-206.

Bykov VJ, Sheehan JM, Hemminki K, and Young AR (1999). In situ repair of cyclobutane pyrimidine dimers and 6-4 photoproducts in human skin exposed to solar simulating radiation. J Invest Dermatol 112:326-331.

Chadwick CA, Potten CS, Nikaido O, Matsunaga T, Proby C, and Young AR (1995). The detection of cyclobutane thymine dimers, (6-4) photolesions and the Dewar photoisomers in sections of UV-irradiated human skin using specific antibodies, and the demonstration of depth penetration effects. $J$ Photochem Photobiol B 28:163-170.

Gale JM and Smerdon MJ (1990). UV induced (6-4) photoproducts are distributed differently than cyclobutane dimers in nucleosomes. Photochem Photobiol 51:411-417.

Gaubatz JW and Tan BH (1994). Aging affects the levels of DNA damage in postmitotic cells. Ann NY Acad Sci 719:97107.

Gobbel GT, Bellinzona M, Vogt AR, Gupta N, Fike JR, and Chan PH (1998). Response of postmitotic neurons to $X$-irradiation: implications for the role of DNA damage in neuronal apoptosis. J Neurosci 18:147-155.

Hadjiolov D and Venkov L (1975). Strand breakage in rat brain DNA and its repair induced by ethylnitrosourea in vivo. $Z$ Krebsforsch 84:223-225.

Ishikawa T, Takayama S, and Kitagawa T (1978a). Autoradiographic demonstration of DNA repair synthesis in ganglion cells of aquarium fish at various ages in vivo. Virchows Arch B Cell Path 28:235-242.

Ishikawa T, Takayama S, and Kitagawa T (1978b). DNA repair synthesis in rat retinal ganglion cells treated with chemical carcinogens or ultraviolet light in vitro, with special reference to aging and repair level. J Natl Cancer Inst 61:1101-1105.

Korr H, Koeser K, Oldenkott S, Schmidt H, and Schultze B (1989). X-ray dose-effect relationship on unscheduled DNA synthesis and spontaneous unscheduled DNA synthesis in mouse brain cells studied in vivo. Radiat Environ Biophys 28:13-26.

Korr H, Philippi V, Helg C, Schiefer J, Graeber MB, and Kreutzberg GW (1997). Unscheduled DNA synthesis and mitochondrial DNA synthetic rate following injury of the facial nerve. Acta Neuropahtol 94:557-566.

Korr $\mathrm{H}$ and Schultze B (1989). Unscheduled DNA synthesis in various types of cells of the mouse brain in vivo. Exp Brain Res 74:573-578.

Mazzarello P, Poloni M, Spadari S, and Focher F (1992). DNA repair mechanisms in neurological diseases: facts and hypotheses. J Neurol Sci 112:4-14.

McCready S and Cox B (1993). Repair of (6-4) photoproducts in Saccharomyces cervisiae. Mutat Res 293:233-240.

Mitchell DL, Cleaver JE, Lowery MP, and Hewitt RR (1995). Induction and repair of (6-4) photoproducts in normal human and xeroderma pigmentosum variant cells during the cell cycle. Mutat Res 337:161-167.

Mitchell DL, Nguyen TD, and Cleaver JE (1990). Nonrandom induction of pyrimidine-pyrimidone $(6-4)$ photoproducts in ultraviolet-irradiated human chromatin. J Biol Chem 265: 5353-5356.

Moan J and Peak MJ (1989). Effects of UV radiation on cells. J Photochem Photobiol B 4:21-34.

Mori T, Nakane M, Hattori T, Matsunaga T, Ihara M, and Nikaido O (1991). Simultaneous establishment of monoclonal antibodies specific for either cyclobutane pyrimidine dimer or (6-4) photoproduct from the same mouse immunized with ultravioletirradiated DNA. Photochem Photobiol 54:225-232.

Morris EJ, Dreixler JC, Cheng KY, Wilson PM, Gin RM, and Geller HM (1999). Optimization of single-cell gel electrophoresis (SCGE) for quantitative analysis of neuronal DNA damage. Biotechniques 26:282-283, 286-289. 
Nakatsuru Y, Matsukuma S, Nemoto N, Sugano H, Sekiguchi $\mathrm{M}$, and Ishikawa T (1993). $\mathrm{O}^{6}$-methylguanine-DNA methyltransferase protects against nitrosamine-induced hepatocarcinogenesis. Proc Natl Acad Sci USA 90:6468-6472.

Oda H, Zhang S, Tsurutani N, Shimizu S, Nakatsuru Y, Aizawa S, and Ishikawa T (1997). Loss of p53 is an early event in induction of brain tumors in mice by transplacental carcinogen exposure. Cancer Res 57:646-650.

Qin X, Zhang S, Nakatsuru Y, Oda H, Yamazaki Y, Suzuki T, Nikaido O, and Ishikawa T (1994). Detection of active UVphotoproduct repair in monkey skin in vivo by quantitative immunohistochemistry. Cancer Lett 83:291-298.

Qin X, Zhang S, Oda H, Nakatsuru Y, Shimizu S, Yamazaki Y, Nikaido O, and Ishikawa T (1995). Quantitative detection of ultraviolet light-induced photoproducts in mouse skin by immunohistochemistry. Jpn J Cancer Res 86:1041-1048.

Qin X, Zhang S, Zarkovic M, Nakatsuru Y, Shimizu S, Yamazaki Y, Oda H, Nikaido O, and Ishikawa T (1996). Detection of ultraviolet photoproducts in mouse skin exposed to natural sunlight. Jpn J Cancer Res 87:685-690.

Rao KS (1993). Genomic damage and its repair in young and aging brain. Mol Neurobiol 7:23-48.

Rao KS and Loeb LA (1992). DNA damage and repair in brain:relationship to aging. Mutat Res 275:317-329.
Scherini E and Mares V (1993). Renewal of DNA in Purkinje cell nuclei of mouse cerebellum. A 9-month follow-up autoradiographic study. Physiol Res 42:193-199.

Schmitz C, Axmacher B, Zunker U, and Korr H (1999). Age-related changes of DNA repair and mitochondrial DNA synthesis in mouse brain. Acta Neuropathol 97:71-81.

Setlow RB (1974). The wavelengths in sunlight effective in producing skin cancer: a theoretical analysis. Proc Natl Acad Sci USA 71:3363-3366.

Subrahamanyam K and Rao KS (1991). Ultraviolet lightinduced unscheduled DNA-synthesis in isolated neurons of rat brain of different ages. Mech Ageing Dev 57:283-291.

Wheeler KT and Lett JT (1972). Formation and rejoining of DNA strand breaks in irradiated neurons in vivo. Radiat Res 52:59-67.

Wheeler KT and Lett JT (1974). On the possibility that DNA repair is related to age in non-dividing cells. Proc Natl Acad Sci USA 71:1862-1865.

Young AR, Chadwick CA, Harrison GI, Hawk JLM, Nikaido O, and Potten CS (1996). The in situ repair kinetics of epidermal thymine dimers and 6-4 photoproducts in human skin types I and II. J Invest Dermatol 106:1307-1313. 